\title{
Evaluation and treatment of frey syndrome
}

\begin{abstract}
Frey syndrome (FS) is a localized cervicofacial hyperhidrosis and erythema during mastication in the preauricular area, which corresponds to the region of distribution of the auriculotemporal nerve. FS occurs most commonly after surgical procedures involving the parotid gland but may also be encountered after neck dissection or rhytidectomy procedures, or as a result of trauma to the preauricular region. Misdirected nervous regeneration is thought to be the underlying cause of this syndrome. FS is confirmed with the Minor's test, also known as the starch-iodine test. Several surgical approaches including increased skin thickness flap, sternocleidomastoid muscle flap, superficial musculoaponeurotic system flap, platysma muscle flap, temporal muscle fascia flap, the use of acellular dermal matrix or free fat grafts are described to prevent the development of FS. Although the local fascia and muscle flaps have their own share of limitations and risks of complications, several authors previously reported decrease in the incidence of FS after utilization of these techniques. Once FS develops, it may be managed medically or surgically. Medical management comprises of topical application of antiperspirants, or injections with alcohol, scopolamine, glycopyrrolate, or Botulinum toxin type A in the affected area. Surgical treatment options including transection of the auriculotemporal nerve, tympanic nerve, and greater auricular nerve, are also described in the literature although they are less commonly practiced for the management of FS.
\end{abstract}

Keywords: frey syndrome, auriculotemporal syndrome, gustatory sweating, parotidectomy, salivary glands
Volume 8 Issue 6 - 2017

\author{
Mustafa Daloglu,' Nelli Yıldırımyan, ${ }^{2}$ Mehmet \\ Ali Altay ${ }^{2}$ \\ 'Clinic of Otolaryngology Antalya Ataturk State Hospital,Turkey \\ ${ }^{2}$ Department of Oral and Maxillofacial Surgery Faculty of \\ Dentistry Akdeniz University, Turkey
}

Correspondence: Mustafa Daloğlu, Antalya Ataturk State Hospital, Ucgen Mahallesi,Anafartalar Cad., 07040 Muratpasa/ Antalya, Turkey, Tel +905063035464,

Email drmustafadalogulu@gmail.com

Received: June 24, 2017 | Published: October 18, 2017

\section{Abbreviations: FS, frey syndrome; SCMMF, sternocleidomastoid muscle flap; SMAS, superficial} musculoaponeurotic system; BTX-A, botulinum toxin type A

\section{Introduction}

Hyperhidrosis or gustatory sweating in the region of the parotid gland was first mentioned by Kastremsky in 1740, Duphenix in 1757 and then by Baillarger in 1853. It was, however, the Polish neurologist Lucja Frey who described this condition as a new syndrome in 1923.,2 Frey syndrome (FS) is characterized by localized cervicofacial hyperhidrosis and erythema during mastication in the area of distribution of the involved auriculotemporal nerve, a branch of the mandibular nerve (V3) ${ }^{3}$. Misdirected nervous regeneration, mostly as a result of parotid surgery, is thought to be the underlying cause of FS. ${ }^{4,5}$

\section{Discussion}

Frey syndrome or auriculotemporal nerve syndrome is defined as an auriculotemporal nerve dysfunction. Its main symptoms are transient flushing, warmth and sweating of the face in the preauricular area in response to mastication or a salivary stimulus. ${ }^{1,6}$ These symptoms arise characteristically a few seconds after eating and last for a few minutes. Acidic, spicy and sour foods are more commonly reported to induce symptoms. ${ }^{1}$ FS usually manifests after surgical procedures involving the parotid gland but may also less commonly occur after neck dissection or rhytidectomy procedures, or as a result of trauma to the preauricular region. ${ }^{6}$

The incidence of FS after parotid surgery varies highly in the literature and is reported to be between $5-100 \%{ }^{7,8}$ This divergence depends on several factors including the study design, the use of preventive surgical treatments, and the criteria used for diagnosis. ${ }^{9}$ The size of a parotid tumor may also be a possible predictor for FS development, with a nearly doubled incidence in patients with tumor size of $4 \mathrm{~cm}$ or greater..$^{10}$ Overall, the mean worldwide incidence of FS development after surgical procedures involving the parotid gland is approximately $66 \%$. $^{11,12}$

Anamnesis and medical history, which may reveal previous parotid surgery play an important role in the diagnosis of FS1. The confirmation of FS may be done with the Minor's test (starch-iodine test). The test is done by first painting the patient's post-surgical affected region with iodine and when dried, applying dry starch to the painted area. Then the patient is given a salivary stimulus. The presence of sweat along with the pre-applied iodine will make the starch turn blue/brown. ${ }^{6}$ Although it is considered to be the most effective test to diagnose FS, it still has several limitations including the possible effect of room temperature on sweating. It should be kept in mind that without the use of a negative control in warm temperatures, false positive results may occur. ${ }^{13}$

In order to avoid FS, several surgical preventive methods are described aiming to create a barrier between the parotidectomy bed and the skin. ${ }^{14}$ These methods are increased skin thickness flaps, local fascia or muscle flaps, such as sternocleidomastoid muscle flap (SCMMF), superficial musculoaponeurotic system (SMAS) flap, platysma muscle flap, or temporal muscle fascia flap, or the use of acellular dermal matrix or free fat grafts. ${ }^{6,14}$ Many studies indicate that these preventive surgical procedures are associated with a decrease in the clinical symptoms of FS. ${ }^{14-18}$ However, there are also several others, which found no evidence of such an association. ${ }^{19,20}$ Like any other surgical procedure, these procedures have their own share of limitations and risks of complications. The injury of the spinal accessory nerve is a well-recognized complication of SCMMF interposition. ${ }^{21}$ Temporoparietal fascia flap may cause functional complications such as facial nerve paralysis, haematoma and cosmetic complications including alopecia and extension of the surgical scar in the temporal region, even though its use is reported to decrease the incidence of FS..$^{22,23}$ The use of SMAS flaps on the 
other hand, are limited to benign parotid diseases, due to anatomical considerations..$^{24,25}$

Once FS develops, post-surgical interventions are focused more on ameliorating the symptoms, rather than providing an actual cure for FS. These interventions may be medical or surgical. Medical management options include topical application of antiperspirants, or injections with alcohol, scopolamine, glycopyrrolate, or Botulinum toxin type A (BTX-A) at the affected area. ${ }^{6}$ The use of BTX-A has been considered an effective alternative to preventive surgical procedures for the past two decades. According to a recent metaanalysis of 22 published articles on the subject, BTX-A is shown to improve the symptoms of patients with FS, even in recurrent cases, with acceptable efficacy and safety. ${ }^{2}$ Surgical treatment options, such as transection of the auriculotemporal nerve, tympanic nerve, and greater auricular nerve, are also described in the literature but remain less commonly practiced. ${ }^{6}$ Although recent studies report complete resolution in more than $50 \%$ of FS patients, who underwent the transposition procedure, these studies are limited in number and too varied to warrant conclusions. ${ }^{26}$ It should also be kept in mind that these surgical alternatives possess an increased risk of facial nerve injury, therefore should only be considered for cases that are refractory to conservative treatment options. ${ }^{6}$

\section{Conclusion}

Frey syndrome is a post-operative condition, which may occur following parotid gland surgery, rhytidectomy, neck dissection or trauma to the preauricular area. ${ }^{6}$ It presents with gustatory sweating and flushing of the skin on the lateral aspect of the face and upper neck, which corresponds to the area of distribution of the auriculotemporal nerve. ${ }^{14}$ Several surgical techniques are utilized to prevent development of FS aiming to provide a barrier between the skin and surgical field. ${ }^{6}$ FS may be managed medically or surgically, and among the alternatives, subcutaneous botulinum toxin type A injections stand out as a highly effective and safe option.

\section{Acknowledgments}

Not applicable.

\section{Conflicts of interest}

Not applicable.

\section{Funding}

None.

\section{References}

1. Blanc S, Bourrier T, Boralevi $\mathrm{F}$, et al. Frey Syndrome. J Pediatr. 2016;174:211-217.e212.

2. Xie S, Wang K, Xu T, et al. fficacy and safety of botulinum toxin type A for treatment of Frey's syndrome: evidence from 22 published articles. Cancer Med. 2015;4(11):1639-1650.

3. Gardner WJ. Auriculotemporal syndrome. $J$ Am Med Assoc $1956 ; 160: 272$.

4. Ford FR. Phenomena due to misdirection of regenerating fibers of cranial, spinal and autonomic nerves. Arch Surg. 1938;36(3):480.

5. Laccourreye O, Muscatelo L, Naude C, et al. Botulinum Toxin Type a for Frey's Syndrome: A Preliminary Prospective Study. Ann Otol Rhinol Laryngol. 1998;107(1):52-55.

6. Motz KM, Kim YJ. Auriculotemporal Syndrome (Frey Syndrome) Otolaryngol Clin North Am. 2016;49(2):501-509.
7. Farrell ML, Kalnins IK. Frey's syndrome following parotid surgery. ANZ J Surg. 1991;61(4):295-301.

8. Linder TE, Huber A, Schmid S. Frey's Syndrome After Parotidectomy: A Retrospective and Prospective Analysis. Laryngoscope. 1997;107(11 Pt 1):1496-1501.

9. Rustemeyer J, Eufinger H, Bremerich A. The incidence of Frey's syndrome. J Craniomaxillofac Surg . 2008;36(1):34-37.

10. Lee CC, Chan RC, Chan JY. Predictors for Frey Syndrome Development After Parotidectomy-Size Does Matter. Annals of Plastic Surgery. 2017; doi: 10.1097/SAP.0000000000000993.

11. Laage-Hellman JE. Gustatory Sweating and Flushing After Conservative Parotidectomy. Acta Otolaryngol. 1957;48(3):234-252.

12. Laccourreye H, Laccourreye $\mathrm{O}$, Cauchois Rg, et al. Total Conservative Parotidectomy for Primary Benign Pleomorphic Adenoma of the Parotid Gland. Laryngoscope. 1994;104(12):1487-1494.

13. Tuncel A. A comparison of incidence of Frey's syndrome diagnosed based on clinical signs and Minor's test after parotis surgery. Kulak Burun Bogaz Ihtis Derg. 2012;22(4):200-206.

14. Dulguerov N, Makni A, Dulguerov P. The superficial musculoaponeurotic system flap in the prevention of Frey syndrome: A meta-analysis. Laryngoscope. 2016;126(7):1581-1584.

15. Sharma R. Prevention of Frey syndrome with superficial temporal fascia interpositioning: a retrospective study. Int J Oral Maxillofac Surg. 2014;43(4):413-417.

16. Xiao M, Shi L, Liu YS. Effectiveness of acellular dermal matrix and parotid fascia in preventing Frey's syndrome: Meta analysis]. Shanghai Kou Qiang Yi Xue. 2014;23(5):628-633.

17. Mohamed M, Nofal A. Sternocleidomastoid Muscle Flap after Parotidectomy. Int Arch Otorhinolaryngol. 2015;19(4):319-324.

18. Hayashi A, Mochizuki M, Suda S, et al. Effectiveness of platysma muscle flap in preventing Frey syndrome and depressive deformities after parotidectomy. Journal of Plastic, Reconstructive \& Aesthetic Surgery. 2016;69(5):663-672.

19. Grosheva M, Horstmann L, Volk GF, et al. Frey's syndrome after superficial parotidectomy: role of the sternocleidomastoid muscle flap: a prospective nonrandomized controlled trial. Am J Surg. 2016;212(4):740-747.e741.

20. Lafont M, Whyte A, Whyte J, et al. Frey syndrome: factors influencing the time to event. Int J Oral Maxillofac Surg. 2015;44(7):834-839.

21. To EW. Sternomastoid muscle flap for parotidectomy: the pros and cons. Br J Plast Surg. 2002;55(1):88-89.

22. Ahmed OA, Kolhe PS. Prevention of Frey's syndrome and volume deficit after parotidectomy using the superficial temporal artery fascial flap. Br J Plast Surg. 1999;52(4):256-260.

23. Cesteleyn L, Helman J, King S, et al. Temporoparietal fascia flaps and superficial musculoaponeurotic system plication in parotid surgery reduces Frey's syndrome. J Oral Maxillofac Surg . 2002;60(11):1284-1297

24. Casani AP, Cerchiai N, Dallan I, et al. Benign tumours affecting the deep lobe of the parotid gland: how to select the optimal surgical approach. Acta Otorhinolaryngol Ital . 2015;35(2): 80-87.

25. Chulam TC, Noronha Francisco AL, Goncalves Filho J, et al. Warthin's tumour of the parotid gland: our experience. Acta Otorhinolaryngol Ital. 2013;33(6):393-397.

26. Dai XM, Liu H, He J, et al. Treatment of postparotidectomy Frey syndrome with the interposition of temporalis fascia and sternocleidomastoid flaps. Oral Surg Oral Med Oral Pathol Oral Radiol. 2015;119(5):514-521. 